\title{
As vantagens da História Cruzada para o estudo da História de Esparta no período clássico
}

Luis Filipe Bantim de Assumpção

Universidade de Vassouras / Universidade Federal do Estado do Rio de Janeiro, Brasil.

lbantim@yahoo.com.br

Recibido: 24/2/2020. Aceptado: 11/8/2020

\begin{abstract}
Resumo
A relação política das póleis no interior da Hélade sempre foi inevitável diante do mar Mediterrâneo, visto como um espaço relacional de dimensões específicas e limitadas. Diante disso, objetivamos analisar as relações políticas do navarco esparciata Lisandro na Hélade do período clássico por meio do arcabouço teórico da Análise do Discurso francesa e da Teoria de Redes, bem como pelo viés comparativista da História Cruzada. Nesse sentido, propomos que uma investigação munida de indícios de múltiplas temporalidades e espacialidades podem nos fornecer mecanismos para superar a tendência atenocêntrica da historiografia que considerou Lisandro e o basileús Agesilau II como os únicos responsáveis pela desestruturação de Esparta.
\end{abstract}

Palavras-chave: Esparta, Lisandro, História Cruzada.

\section{Advantages of Histoire Croisée for the study of Spartan History in the Classical Period}

\begin{abstract}
The political relationship between the Greek poleis were comprehensible because of the Mediterranean Sea, a relational space of a limited dimension. Bearing in mind this situation, our aim is to analyse the political relationship carried out by the spartiate navarch Lysander in Greece during the Classical period through the theoretical framework of the French Discourse Analysis and Network Theory, and the comparative perspective offered by the Histoire Croisée. We propose that a research on multiple temporalities and specialities will help to overcome the Athenocentric historiographical trend that considers Lysander and king Agesilaos II as the solely responsible for the disruption of their society.
\end{abstract}

Keywords: Sparta, Lysander, Histoire Croisée. 


\section{As póleis no interior da Hélade: um espaço de relações políticas}

Dentre as comunidades helênicas da Antiguidade clássica, ${ }^{1}$ Esparta foi considerada uma das mais importantes. Isso se deu, já no período clássico, quando os esparciatas foram identificados como "artistas na arte de guerrear", segundo Xenofonte (Lac. 13. 5), ou mesmo como os helenos que respeitavam o sagrado acima dos seus deveres com os homens (Hdt. V. 63. 2). Entretanto, essa polarização não nos ajuda a perceber a singularidade das práticas político-culturais espartanas, visto que o discurso dos autores antigos lida com as necessidades inerentes ao contexto social e a comunidade discursiva ${ }^{2}$ em que se encontravam.

Dito isso, objetivamos apresentar uma alternativa de pesquisa diante dos indícios literários que versaram sobre Esparta, no período clássico, de tal maneira que possamos refutar perspectivas inerentes à historiografia atenocêntrica hegemônica. ${ }^{3}$ Para tanto, selecionamos a desestruturação política de Esparta como o recorte temporal para se pensar a sua trajetória histórica. Para esta tendência historiográfica Esparta se enfraqueceu e perdeu a sua supremacia pelas ações do navarco Lisandro e do basileús Agesilau II. ${ }^{4}$ Nesse sentido, utilizamos os pressupostos comparativistas da História Cruzada, associados ao arcabouço conceitual da disciplina da Análise do Discurso francesa mesclado à Teoria de Redes de Charles Kadushin para propor uma nova interpretação deste imbróglio historiográfico.

Com isso, consideramos que a tradição historiográfica de Tucídides serviu para legitimar uma representação atenocêntrica de Esparta, a qual passou a ser considerada a "inimiga natural" de Atenas. Via de exemplo Tucídides (II. 39. 1) mobilizou a imagem de Péricles para promover uma cena enunciativa, na qual o discurso desse comandante representasse o ideal democrático ateniense, em oposição às atitudes da Confederação do Peloponeso, liderada por Esparta. Portanto, a cena enunciativa criada por Tucídides tendo Péricles como a sua personagem central, reforça a identidade ateniense e destaca o motivo pelo o qual estavam lutando. Segundo Dominique Maingueneau (1997, p. 34), a cena enunciativa se utiliza da metáfora teatral para refletir uma parte da realidade, mobilizando uma cronografia - a Guerra do Peloponeso -, uma topografia - Atenas - e um momento propício para o surgimento do discurso - a tentativa de mobilizar os atenienses a continuar a combater na guerra contra os peloponésios, após o primeiro ano de conflito -.

A definição proposta por Maingueneau nos permite correlacionar a cena enunciativa com o conceito de representação, ambos tomados como referência ao espaço teatral.

1 Todas as datas neste texto se referem ao período "antes de Cristo", com exceção daquelas que indicarmos o contrário.

2 Este conceito foi concebido por Maingueneau (1997, p. 56) como o grupo ou a organização de grupos no interior dos quais são produzidos os discursos. Entretanto, a comunidade discursiva não corresponde somente aos grupos (instituições e relações entre agentes sociais), mas também a tudo aquilo que lida com a organização material dos modos de vida.

3 Destacamos aqui Chester Starr (1965), Claude Mossé (1968) e Moses Finley (1981), cujos escritos foram importantes para o desenvolvimento das pesquisas sobre Antiguidade clássica, mas defenderam uma percepção demasiadamente polarizada dos feitos de Esparta, em virtude do enfoque demasiadamente atenocêntrico. Se pensarmos a dinâmica da Guerra do Peloponeso, por exemplo, Athens and Sparta: Constructing Greek Political and Social History, from 478 BC. de Anton Powell (2001), a série elaborada por Donald Kagan, que inclui The Outbreak of the Peloponnesian War (1969), The Archidamian War (1974), The Peace of Nicias and the Sicilian Expedition (1981) e The Fall of the Athenian Empire (1987); e Victor Davis Hanson com Uma Guerra Sem Igual (2012), são obras que consideraram este conflito como de ordem ideológica entre uma Atenas democrática e uma Esparta oligárquica. Essa tendência é comumente verificável nos livros didáticos do Ensino Básico brasileiro.

4 Charles Hamilton (1979; 1991) e Paul Cartledge (1987) se inserem no bojo de uma historiografia tradicionalista - a qual também se constitui por autores outros como, Geoffrey de Ste Croix (1972), Ephraim David (1981), entre outros -. Esta tendência historiográfica considerou somente o momento da vitória peloponésia sobre os atenienses na Guerra do Peloponeso para edificarem uma investigação objetiva das ações e interações de Esparta com a Hélade. Esses autores, ao tomarem os efeitos imediatos das atitudes de Lisandro e do futuro basileús Agesilau, consideraram que este foi o culpado pela desestruturação dos valores e da organização político-social espartana. 
Logo, Tucídides construiu uma representação de Péricles que partiu das imagens mentais que a sua audiência teria do verdadeiro comandante e de sua oração fúnebre. ${ }^{5}$ Diante disso, Tucídides veiculou a imagem de que Esparta era uma sociedade isolada e, para assegurar os seus costumes, expulsava os estrangeiros de seu território. Essa ideia do isolamento espartano foi ampliada com uma passagem anterior da mesma obra:

As cidades fundadas mais recentemente, quando a navegação afinal tornou-se mais segura, e que estavam consequentemente começando a ter recursos excedentes, foram construídas no litoral e nos istmos ocupados e isolados por muralhas, com vistas ao comércio e à proteção dos habitantes contra seus vizinhos. As cidades mais antigas, todavia, tanto nas ilhas quanto no continente, haviam sido construídas a maior distância do mar por causa da pirataria que predominou por longo tempo, pois os piratas não somente pilhavam-se uns aos outros, mas também os habitantes do litoral, mesmo os que não viajavam por mar e até hoje permanecem no interior (Thuc. I. 7).

Tucídides caracterizou que a posição geográfica de Esparta tinha um objetivo específico, além de ressaltar que esta seria uma das póleis mais antigas do continente. Nesse sentido, o autor exaltou os "feitos inovadores" de Atenas que, além de ser uma comunidade mais nova, pôde se estabelecer no litoral, em contato com outras regiões e enriquecendo com as suas atividades marítimas.

O discurso de Péricles na obra de Tucídides é um elogio à identidade de Atenas e aquilo pelo que lutavam no início da guerra, em detrimento da espartana. Se considerarmos o lugar social de Tucídides e o fato deste ser ateniense em pleno conflito que se propôs a relatar, muito do seu posicionamento se torna justificável diante de sua comunidade discursiva. Ainda assim, Tucídides destacou a importância da interação das póleis com o seu entorno para o estabelecimento de práticas políticas, sociais e econômicas, chegando a estabelecer uma relação de causa e efeito entre a cidade, o seu território e os espaços geograficamente contíguos. De todo modo, cabe-nos afirmar que Esparta, assim como as demais póleis, somente existiu em virtude da interação com outras áreas.

Esse viés salienta a importância das redes político-sociais para a organização das póleis helênicas. Nesse sentido, a identidade espartana foi construída pelo lugar que ocupou no interior das redes políticas, sociais, econômicas e culturais da Hélade continental e do mar Egeu. Tal assertiva nos ajuda a lançar novas interpretações documentais e propostas de análise historiográfica sobre o isolamento de Esparta. A própria organização da rede político-militar reconhecida como Confederação do Peloponeso - por volta do século VII - ocorreu pela expansão dos interesses espartanos para além de seu território. No que diz respeito às conexões entre os nós ${ }^{6}$ da Confederação do Peloponeso e da Hélade, concebemos que o papel exercido por cada pólis nesse ambiente relacional influenciava na configuração das redes mediterrânicas. Com Esparta não foi diferente, pois os anos que vivenciou à Guerra do Peloponeso transformaram as suas práticas, costumes e valores de modo irreversível.

5 Segundo Francisco Murari Pires (2006, p. 293), Tucídides se utilizou de uma retórica da objetividade para assegurar a imagem de veracidade a sua obra, em uma possível oposição a Heródoto. Para isso, o autor explicitou o seu método de pesquisa e análise, o qual cria com a mesma habilidade dos escritos herodoteanos, embora tente "racionalizar" elementos que outrora seriam atribuídos ao acaso ou aos deuses. Por outro lado, Murari (2006, pp. 349-355) sugere que Péricles seria o modelo de líder político ideal para Tucídides pela capacidade de liderança político-militar e por conter os interesses do dêmos mesmo diante da assembleia. Já Martha Taylor (2010, passim) enfatizou que o Péricles de Tucídides pretendia representar a grandeza ateniense alcançada com as atividades marítimas, bem como o compromisso com os cidadãos desta pólis, cujos esforços tornaram-na um modelo para os demais helenos. 6 Este é um conceito atrelado a Teoria de Redes, se referindo aos sujeitos, sociedades e ou grupos que se relacionam mutuamente e criam um grande complexo de trocas e interações políticas, sociais, econômicas e culturais para a circulação de bens, recursos e informações. Como os pressupostos teóricos lidam com a ideia de se formar uma rede, semelhante as de pesca, o nó corresponde a uma dessas unidades mínimas que se relacionam por meio de fios/conexões e juntas edificam algo muito maior. 
Contudo, o fato das póleis serem caracterizadas como helênicas impediu que muitos estudiosos abordassem as diferenças imediatas que existiram entre elas, levando-nos a pensar a Hélade como uma unidade territorial distinta das culturas que a rodeava. Tal assertiva nos leva a pensar a Hélade como uma entidade plural, edificada pelas múltiplas culturas que a compunha e impossibilitando uma perspectiva simplista e unitária para lidar com as sociedades que ali existiram.

Nesse sentido, Lawrence Tritle (1997, pp. 1-3) enfatizou que a Guerra do Peloponeso foi um conflito de característica interpolíade, não podendo ser compreendido fora do contexto das relações políticas entre as póleis. Essa perspectiva foi trabalhada por Polly Low (2007, pp. 1-3), chegando a pontuar que os helenos do período clássico não desenvolveram um manual que discorresse sobre as relações políticas entre as póleis. Todavia, em quase todos os seus escritos temos as interações entre os territórios da Hélade e de outras entidades culturais, ressaltando que os helenos se representavam de forma conectada e relacional com as demais comunidades do Mediterrâneo.

Dessa maneira, sugerimos que Tucídides caracterizou Esparta como uma pólis que subverteu os seus valores ancestrais por se corromper com a guerra, fazendo com que esta comunidade perdesse a eunomía. Enquanto um ateniense em meio a um conflito político-militar de grandes proporções, era de se esperar que Tucídides estivesse alinhado à sua formação discursiva, destacando que os líderes de Atenas não comandavam como Péricles e haviam se distanciado da magnitude políade alcançada por este. Dominique Maingueneau (1997, p. 14) argumentou que a formação discursiva seria um conjunto de regras anônimas expressas em conformidade ao contexto e ao território em um dado período histórico, sendo responsável por fornecer e assegurar as condições de exercício de sua enunciação discursiva. Essa concepção se vincula diretamente ao conceito de lugar social de Michel de Certeau. Este (De Certeau, 1982, p. 66) definiu o lugar social como o ambiente que estabelece o que pode e o que não pode ser feito/dito. No caso de Tucídides, o seu lugar social seria o posto de um exilado ateniense que vivenciou o contexto de guerra e passou a se opor aos excessos de uma democracia radical, cujos esforços levariam Atenas à ruína.

De todo modo, o ateniense se utilizou dos seus escritos como uma propaganda política ou mesmo uma denúncia aos problemas vivenciados ou perpetrados por sua pátria, mas também, daqueles que os espartanos realizaram. Ainda que não partilhasse de um governo liderado pela multidão, Tucídides considerou que a guerra corrompeu a oligarquia espartana, sendo este um indício da sua descrença quanto aos benefícios do conflito que se abatia nos helenos (Raaflaub, 2006, pp. 195-220; Canfora, 2016). Ainda assim, Tucídides descreveu a "história de seu tempo", justificando e denunciando as ações dos atenienses e dos lacedemônios, que ao invés de liderarem visando o bem-comum, almejavam unicamente os seus interesses particulares. Essa perspectiva crítica teria se desenvolvido quando Tucídides esteve no exílio, posto que atuava como um expectador daquilo que ocorria (Canfora, 2016). É nesse sentido que, em certa medida, Péricles representaria o ideal democrático partilhado por Tucídides, no qual o melhor dos cidadãos poderia guiar adequadamente o dêmos, mesmo não sendo uma monarquia/tirania.

Se considerarmos que Tucídides escreveu nos últimos anos da guerra, é possível que tenha tentado denunciar os problemas advindos de atitudes pouco interessadas com

7 Kostas Vlassopoulos (2009, pp. 13-14) reforça essa ideia ao declarar que a maioria dos estudos sobre a Antiguidade helênica foi realizada visando perspectivas assimétricas, voltadas para a cultura das póleis e ignorando as entidades culturais com as quais estas interagiram e fomentaram uma identidade fluida. Anteriormente, Hans Beck (2008, pp. 1-2) expôs que as intensas disputas vivenciadas na Hélade inviabilizavam análises de comunidades e culturas isoladas, e com as quais os helenos se relacionaram. Portanto, o fundamental era conceber as conexões que as cidades gregas e não-gregas estabeleceram entre si, edificando aquilo que ficou conhecido como "História da Hélade". 
o fim deste conflito. Assim, sugerimos que Tucídides serviu de referencial para se pensar o ideal pan-helênico que se desenvolverá no século IV. ${ }^{8}$ Como os peloponésios angariaram o apoio de Dario II e Atenas passou por inúmeros reveses - como o desastre da expedição da Sicília em 413 e a revolta oligárquica de 411 -, o discurso de Tucídides enalteceu os prejuízos de uma atitude conjunta com os persas, de tal maneira que a sua audiência verificasse os danos inerentes àquela realidade bélica. Dessa maneira, toda a obra de Tucídides destaca a natureza relacional dos helenos, seja em guerra seja na paz, e inviabiliza pensarmos que havia comunidades no Mediterrâneo capazes de se isolarem ou se absterem completamente da Guerra do Peloponeso.

Esta lógica relacional nos remete a Platão no Fédon, no qual Sócrates acreditava que o mundo era muito maior do que o conhecido na época e, por isso, os helenos eram como formigas ou sapos ao redor de uma pequena poça, o Mediterrâneo:

Eu acredito que a Terra é muito grande e nós que moramos entre as colunas de Héracles e o rio Fásis vivemos em uma pequena parte desta sobre o mar, como formigas ou sapos em uma poça, e que muitas pessoas vivem em muitas outras regiões (PI. Phd. 109a-109b).

As considerações atribuídas a Sócrates por Platão nos permite conjeturar que as relações políticas entre as póleis eram inevitáveis por vivenciarem um espaço geográfico muito bem delimitado. Este viés se relaciona aos estudos de Irad Malkin (2011, pp. 10-11) ao declarar que as relações políticas entre as comunidades do Mediterrâneo eram irremediavelmente necessárias, visto que o mar era um recipiente relativo e relacional, no qual os helenos fizeram cruzar os seus interesses, valores e identidades. Malkin chama a atenção para a pluralidade das póleis e pelo fato das suas interações ocorrerem de forma simultânea.

Sendo assim, identificamos que o método da História Cruzada nos ajuda a perceber as relações políticas que Esparta desenvolveu com outros territorios no interior desta "poça d'água" chamada mar Mediterrâneo. Uma vez que as ações políades ocorriam de forma simultânea, temos a necessidade de cruzarmos os dados e os discursos documentais, para aprofundarmos a percepção de nosso objeto. Isto é, a maneira como Esparta articulou as suas relações políticas com outras póleis e como essas interações fomentaram densas redes políticas ${ }^{9}$ ao redor do Egeu com outras comunidades mediterrâneas.

Com isso, o mar Mediterrâneo se constituiu em um espaço relacional por excelência, tornando inevitável o contato entre helenos e não-helenos. A tentativa de tornarmos essa abordagem distinta das demais nos levou a tomar as interações de Esparta, Lisandro e Agesilau no século IV em sincronia às atividades político-sociais de outras póleis no Mediterrâneo. Entretanto, o uso de documentos literários oriundos de períodos históricos para além do clássico denota a diacronia presente em nossa análise, aspecto que a História Cruzada não condena em sua postura investigativa. Sendo assim, é importante que o pesquisador mantenha um ponto de vista externo ao objeto, capaz de abranger e problematizar a totalidade dos indícios documentais na construção de sua pesquisa (Werner e Zimmermann, 2003, pp. 90-91).

8 Desenvolvemos este viés a partir de H. D. Westlake (1971, pp. 315-325), em conformidade a Raaflaub (2006).

9 Kadushin (2012, p. 32) afirmou que as redes densas são mais comuns em pequenos grupos de nós, sendo adjetivada desta forma em virtude da multiplicidade de relações que os seus nós mantêm entre si. A teoria e o método estabelecido por Kadushin foram desenvolvidos para se pensar as redes em sociedades contemporâneas, fazendo com que o autor chame de tradicionais as relações estabelecidas anteriormente a contemporaneidade. Uma vez que Kadushin aborda sociedades em meio a globalização, as redes formadas na Antiguidade nas imediações do Mediterrâneo podem ser definidas como pequenas e densas. 
Embora essa diacronia documental seja criticada por muitos especialistas sobre a História de Esparta, reforçamos, em conformidade a Dominique Maingueneau (1997, pp. 11-12,17), que cada texto foi/é/será produzido no interior de um contexto, sendo produto de um tempo determinado e o resultado dos esforços de muitas mentes. Ao nos utilizarmos do conhecimento da Análise do Discurso por uma via interdisciplinar, defendemos que a diacronia não inviabiliza a produção do conhecimento historiográfico desde que as variáveis espaço-temporais nas quais as obras antigas se inserem sejam consideradas em suas especificidades.

Para evitarmos anacronismos históricos, adotamos uma visão assimétrica de análise que têm a Esparta do século IV e Lisandro como os elementos centrais de nossa abordagem neste artigo, mas que torna essencial a tratamento relacional de outras póleis e atores sociais nas imediações do Mediterrâneo. ${ }^{10}$ Com isso, as trajetórias políticas de Esparta e de Lisandro se modificaram por meio da interação que estabeleceram com as póleis do Egeu e do continente, bem como através da relação com a dinastia Aquemênida. Conjecturando através de Werner e Zimmernann (2003, p. 96), o cruzamento como um princípio ativo e dinâmico é fundamental para entendermos a interação, a circulação e as relações inerentes ao nosso objeto e aos grupos/atores sociais com os quais se vincularam no período clássico. Ressaltamos também que esta abordagem, além de estar formalmente atrelada ao estudo das redes e das relações políticas de Esparta no século IV, têm como pressuposto fundamental confrontar uma concepção particular promovida pela historiografia contemporânea.

Autores como Paul Cartledge (1987), Charles Hamilton (1991) e John Buckler (2003) foram alguns dos que se debruçaram nesta realidade político-social da Hélade no século IV. ${ }^{11}$ Dentre eles, somente Buckler manteve o seu enfoque nas relações políticas de Tebas, enquanto os demais se dedicaram à Esparta. Entretanto, os três pesquisadores expressam algumas ideias comuns, ou seja, eles consideraram que Esparta se desestruturou em virtude das ações de Lisandro e do basileús Agesilau II. Nos intriga o fato destes helenistas não considerarem que Esparta estava inserida em um processo político de grandes proporções que envolvia uma parcela significativa das póleis do Egeu e outras comunidades mediterrânicas. Afinal, as suas obras demonstram que Esparta perdeu a sua hegemonia pelo ímpeto infantil de um governante despreparado e impulsivo, bem como da ganância desmedida de um de seus esparciatas. ${ }^{12}$

Ainda que estes autores tenham desenvolvido estudos elementares sobre a Antiguidade, as suas conclusões foram demasiadamente parciais. Identificamos também que estes seguiram a vertente literária de Plutarco em suas Vida de Lisandro e Vida de Agesilau, onde o beócio caracterizou o navarco e o basileús como dois dos homens mais gananciosos e implacáveis de seu tempo. Essa abordagem historiográfica produziu um julgamento de duas personagens históricas sem considerar as variáveis que se fizeram presentes no contexto histórico da primeira metade do século IV. Dessa forma, as atitudes de Lisandro e de Agesilau em conformidade aos seus próprios interesses, às determinações de sua pólis e às intervenções do período em questão foram fundamentais para a nossa investigação. Em vista disso, as relações e as redes políticas de Lisandro estiveram diretamente vinculadas aos interesses de sua pólis, em um século IV onde a Hélade vivenciava os efeitos de décadas de conflito e desgaste econômico.

10 Este artigo é parte integrante de nossa tese de doutorado defendida junto ao Programa de Pós-graduação em História Comparada em Julho de 2019. Logo, muitas das póleis que se fizeram presentes em nossas considerações serão brevemente comentadas em virtude do espaço que temos para desenvolver este texto.

11 Buckler não foi utilizado como um dos pressupostos desta análise porque o seu enfoque não foi Lisandro e/ou Agesilau, e sim depreciar os feitos do navarco e do Euripôntida para enaltecer as atitudes de Tebas e da Beócia, no século IV.

12 Vide notas 3, 4 e 11. 
Claire Lemercier (2015, pp. 285-291) afirmou que a Teoria de Redes se preocupa com os vínculos formados com as relações entre os sujeitos/sociedades. Para tanto, somente uma análise qualitativa da documentação nos permitirá conceber e reconhecer uma rede "padronizada" de abordagem, passível de uma investigação adequada. Por fim, a autora defendeu que as análises de redes podem fazer cruzar estruturas e instituições, não somente seres humanos e as suas dinâmicas. Charles Kadushin (2012, pp. 3-15) corrobora Lemercier, destacando que o propósito das redes é formar conexões entre pessoas, sociedades e instituições.

Por sua vez, as redes se constituem de relações e dependências mútuas que vinculam pessoas umas às outras. Kadushin (2012, pp. 10-15) declarou que as relações entre atores sociais podem surtir efeitos concomitantes em outras áreas de atuação através da sua dinâmica e do poder que exercem sobre outros indivíduos. Portanto, as relações entre sujeitos geram resultados inesperados e para além do controle dos pontos de maior preponderância de uma rede. A situação comentada pode culminar no desenvolvimento de relações e/ou redes de tensão, as quais são pensadas como uma correspondência direta de relações de reciprocidade.

Tanto Claire Lemercier quanto Charles Kadushin nos levam a conjeturar que a amplitude das redes política e das relações que as fundamenta depende do cruzamento de indícios documentais. Logo, sustentamos que a compreensão das relações políticas de Lisandro e Esparta na primeira metade do século IV se tornou possível com o uso do método comparativo proposto pela História Cruzada. Isso destaca a associação direta entre os pressupostos da Teoria de Redes e os instrumentos metodológicos fornecidos pelos processos relacionais da História Cruzada. Mediante o exposto abordamos brevemente as redes políticas que Esparta edificou com a passagem do século V ao IV com ênfase, inicialmente, nas relações políticas do esparciata Lisandro e como essas influenciaram a emergência política de Agesilau ao trono dos Euripôntidas.

\section{Lisandro e Esparta na passagem do século V para o IV - os antece- dentes do poder político de Agesilau II}

Os últimos anos da Guerra do Peloponeso evidenciavam os desgastes de todas as póleis envolvidas neste conflito. Contudo, os recursos persas investidos na Confederação do Peloponeso somados à habilidade político-militar do esparciata Lisandro contribuíram para a conclusão deste enfrentamento. Lisandro se destacará pelo bom desempenho na frota dos peloponésios e pelo poder político que angariou com homens influentes em toda a Hélade. No entanto, a maior de todas as relações políticas que Lisandro edificou foi com o irmão mais novo de Ágis II, Agesilau, ampliando as redes políticas do Euripôntida pela Hélade e obtendo destaque pessoal entre os lacedemônios.

Esparta iniciou o século IV como a detentora da hegemonia militar entre os helenos ao vencer os atenienses na batalha de Egospótamo (405), marcando o fim da Guerra do Peloponeso e a ascensão política do navarco esparciata Lisandro. A figura de Lisandro pode ser identificada como um efeito direto das transformações pelas quais Esparta e a Hélade perpassaram ao longo da segunda metade do século V. Não estaríamos exagerando ao afirmarmos que Lisandro foi um ator social cujas ações ajudaram a modificar a dinâmica política espartana, tendo em vista que o seu prestígio impactará na realeza lacedemônia. ${ }^{13}$

13 Lisandro e as suas conexões políticas serão responsáveis pela escolha de Agesilau como basileús da dinastia Euripôntida, muito embora este não fosse o herdeiro imediato ao trono (Xen. Hell. III. 3. 3-4; Nep. 17. 1; Plut. Lis. 22. 3; Ages. 3. 3-5). César Fornis (2016, pp. 190-207) discute como Lisandro se valeu da vitória em Egospótamo para ampliar 
O navarco esparciata foi um exemplo de como as transformações espartanas abalaram as determinações políticas que esta pólis passou a tomar no interior da Hélade, com o final da Guerra do Peloponeso. Muito embora Esparta, enquanto pólis, e a sua aristocracia, em particular, mantivessem relações políticas de cunho diplomático com toda a Hélade e com uma parcela da elite persa, Lisandro ampliou esta realidade promovendo uma rede política ainda mais densa e difusora de poderes relacionais. Se considerarmos que Esparta integrava uma rede pequena e densa, no Mediterrâneo, não seria estranho que a sua vitória tenha transformado o cenário político-social helênico. Charles Kadushin (2012, p. 89) destacou que em redes assimétricas a intensidade das conexões entre os elos influencia a estrutura da rede. Deste modo, ainda que a Confederação do Peloponeso tenha se caracterizado como uma rede híbrida, pela mescla entre simetria e assimetria na autoridade de seus membros, ${ }^{14}$ a conclusão da Guerra do Peloponeso - tendo Lisandro como o ator social de maior proeminência - alterou a intensidade das conexões espartanas junto aos helenos. Esta lógica nos leva a problematizar a motivação dos jovens espartanos, como citado por Tucídides (I. 80-85), pois a possibilidade de sucesso na guerra fomentaria a preponderância política de suas respectivas famílias, seja no interior de Esparta seja com a aristocracia da Hélade. Devido as características das redes espartanas, notamos que a influência obtida pelo navarco impactou na dinâmica relacional da Hélade e da Lacedemônia.

No final da década de 410, o Império Aquemênida governado por Dario II se aproximou dos helenos e financiou grande parte dos gastos espartanos na guerra contra Atenas. Isso porque Dario II não se agradava com a influência ateniense em uma parcela dos seus domínios no Egeu. Em 405, o grande rei dos persas enviou o seu filho mais novo, Ciro, na condição de káranos dos domínios aquemênidas no Mediterrâneo, para que auxiliasse os espartanos e os peloponésios no que fosse necessário. Nesse momento, Lisandro - navarco e representante dos interesses de Esparta - formou laços pessoais com Ciro e este beneficiou o esparciata da melhor maneira que pôde com os recursos persas (Xen. Hell. I. 5. 6). Essa aproximação levou a formação de redes políticas por Lisandro que, ao receber o apoio do káranos persa, assegurou os interesses da aristocracia da Jônia. Nos cabe enfatizar que a relação política entre Lisandro e Ciro foi um nítido desdobramento da rede política existente entre Esparta e o Império Aquemênida.

Ao adaptarmos a proposta de Kadushin (2012, pp. 82-83), sugerimos que a relação de Lisandro e Ciro se deu por uma via informal, cujas características fundamentais seriam a busca por segurança, efetividade nas relações e o status pessoal de seu nó central. Contudo, a rede informal se sujeita às intempéries do ambiente externo, justificando a necessidade de Lisandro tomar decisões visando ao benefício de Esparta e dos seus companheiros. Esse posicionamento nos permite afirmar que Lisandro era um nó que participava de diversas redes pequenas, a saber, a de Esparta, a dos seus aliados helenos e a dos persas. Com Ciro a situação se dava na mesma proporção, haja vista que a sua liderança sobre as satrápias da Ásia Menor aumentou o poder dos aquemênidas contra a expansão ateniense, mas também lhe fez angariar apoiadores para os seus interesses pessoais.

as conexões de suas redes políticas. Em seguida, Fornis (2016, pp. 207-209) inicia os argumentos acerca das ações de Lisandro para levar Agesilau a se tornar basileús dos lacedemônios. Scott Rusch (2011, p. 155) afirmou que o poder de Agesilau foi possível graças a influência que Lisandro adquiriu como navarco e promotor das decarquías.

14 A ideia de simetria ocorreu no processo de formação da Confederação do Peloponeso, no qual Esparta foi levada a firmar alianças defensivas com póleis poderosas e que não conseguiu submeter facilmente - como Tegéia. No entanto, a ampliação do poderio espartano fez com que muitas das alianças defensivas firmadas no decorrer do período arcaico e clássico se convertessem em formas de submissão dos peloponésios à vontade de Esparta (Beck e Funke, 2015, pp. 1-29). Esse desequilíbrio se manifestou quando muitos aliados se revoltaram contra Esparta, após a derrota de Leuctra (Funke, 2009, pp. 1-14). 
Por sua vez, Lisandro não perdeu as oportunidades que apareceram, posto que a sua presença entre os aristocratas jônios se tornou necessária e fundamental para assegurar as relações políticas junto a Ciro em prol da Hélade. No que concerne à elite jônica, a posição que passou a ocupar nas relações de forças mediterrânicas fez com que esses homens reconhecessem a debilidade de sua situação e tentassem obter uma segurança mínima para convervarem os seus interesses políticos na rede que envolvia Esparta e o Império Aquemênida. Nesse contexto, as redes políticas de Lisandro junto a homens de renome além da Lacedemônia permitiram que a influência de Esparta também se difundisse. Todavia, não podemos negligenciar o fato de que parte dos inimigos de Lisandro também se tornou opositora de Esparta. Neste caso, em particular, a relação política que Lisandro e Ciro estabeleceram foi de xenía, ${ }^{15}$ e isso pressupunha que os lados envolvidos auxiliassem o amigo estrangeiro em condições de dificuldade.

No interior das redes políticas do Império Aquemênida, Ciro rivalizava com o sátrapa Tissafernes, cujas pretensões pessoais fizeram com que se tornasse aliado dos atenienses. Isso levou os lacedemônios, líderes dos peloponésios, a denunciarem o sátrapa a Ciro que, enquanto káranos, tinha o poder sobre todos os governantes persas da Jônia (Xen. Hell. I. 5. 2). As possíveis motivações de Tissafernes foram expostas por Plutarco (Alc. 25. 1; Lys. 4. 1). Nos dizeres do beócio, Tissafernes foi enviado por Dario II para auxiliar os espartanos em seu conflito contra os atenienses, e não o contrário. Plutarco ainda comentou que a pretensão de Tissafernes seria enfraquecer os helenos para que assim fossem dominados mais facilmente, ao invés de fortalecêlos uns contra os outros.

A postura circunstancial de Tissafernes fez com que diversos autores da Antiguidade o qualificassem como um modelo de homem sem honra, incapaz de obedecer às determinações de seu basileús em decorrência de seus próprios interesses políticoeconômicos. ${ }^{16}$ Embora as críticas a Tissafernes sejam amplas e oriundas de diversos momentos da Antiguidade, recordamos que a comunidade discursiva na qual autores como Tucídides, Xenofonte e Platão ${ }^{17}$ estiveram inseridos consideravam a maioria dos persas como um sinônimo de descomedimento político, social, econômico e cultural. Contudo, como alguns líderes persas foram considerados exemplos de comandantes militares, a figura de Tissafernes materializava a função de materializar todos os excessos esperados de um bárbaro. Por isso, o seu papel na documentação corresponde a um algoz, cujas atitudes são ruins e geram efeitos negativos mesmo quando pensadas em prol de sua sociedade.

Lisandro se destacou entre os helenos ao fornecer-lhes esperanças contra os atenienses após a vitória na batalha de Notium (Hell. Oxy, 4. 3; Xen. Hell. I. 5. 11; Diod. Sic. XIII. 71. 1-4; Plut. Lys. 5. 1-2). O seu êxito foi recompensado pelo apoio dos homens mais influentes da Jônia, mas também do Egeu e da Trácia. A principal controvérsia acerca de Lisandro e das inúmeras formas pelas quais foi representado lida com a sua aparente ânsia pelo poder, seja ele político, seja econômico ou militar. Como o

15 Gabriel Herman (1987, pp. 2-5) afirmou que as conexões políticas entre homens poderosos de diversas localidades da Hélade se caracterizariam como xenía. Esta seria uma prática arcaica, anterior à emergência das póleis, na qual homens de uma mesma estirpe estabeleciam relações de auxílio mútuo para promover interesses materiais e políticos em todo o Mediterrâneo. No entanto, a xenía não detinha fins mercantis, mas sim a possibilidade de se forjar obrigações morais entre os envolvidos. David Konstan (2005, p. 124) definiu a xenía como uma amizade ritualizada mantida pela aristocracia mediterrânica, como um meio de praticar e adornar a sua hospitalidade tradicional mesmo com o advento das póleis e no interior de sistemas democráticos de governo.

16 Tanto nas Helênicas (III. 4. 5-6) quanto no Agesilau (1. 10-13), Xenofonte edifica essa imagem de Tissafernes, a qual parece ter sido partilhada por Diodoro em sua Biblioteca de História (XIV. 26. 5-7) e por Plutarco nas Vidas Paralelas (Ages. 9. 1-2, 10. 3).

17 Temos por hipótese que Tucídides, Xenofonte e Platão foram intertextos para Diodoro e Plutarco, fazendo com que esses manifestassem perspectivas da comunidade discursiva dos primeiros, em períodos posteriores. 
navarco era uma manifestação do poderio militar de Esparta fora do Peloponeso, muitos aristocratas se aproximaram do mesmo almejando benefícios com a pólis lacedemônia.

Nesse caso, as redes políticas que Lisandro formou junto à aristocracia helênica da Ásia poderiam ser compreendidas como hetaireiai. ${ }^{18}$ Nessas confrarias, os homens dotados de uma mesma estirpe ou detentores de poderes políticos, sociais e/ou econômicos semelhantes se reuniam para discutirem assuntos de interesse comum, beneficiando-se mutuamente sempre que necessário. Charles Hamilton (1979, pp. 37-39) afirmou que os aristocratas jônios se vincularam a Lisandro devido à boa relação que este mantinha com Ciro, além de acreditarem que os peloponésios poderiam vencer a guerra, o que lhes daria algum tipo de privilégio político-econômico. Essa situação justifica o que havíamos comentado anteriormente, pois os líderes jônios reconheciam a posição desprestigiada que ocupavam junto aos nós de maior proeminência entre Esparta e o Império Aquemênida e se aproximaram de Lisandro para obter benefícios e segurança. Complementando o exposto, as redes políticas de Lisandro também teriam se estendido à Sicília, onde manteve vínculos pessoais com Dionísio I (Plut. Lys. 2. 5). Sendo assim, Lisandro foi um dos homens mais poderosos da Hélade em decorrência de suas ações e de suas relações políticas nos últimos anos da Guerra do Peloponeso.

Entretanto, Plutarco (Lys. 2. 4) nos informou que Lisandro foi o responsável por introduzir riquezas em abundância no interior de sua pólis, fazendo com que os esparciatas desenvolvessem o vício da ambição. Xenofonte (Lac. 14. 3) destacou que os esparciatas do século IV se orgulhavam de possuírem riquezas, aspecto que outrora foi reprovado e desdenhado por estes. Ao cruzarmos a documentação verificamos que o discurso de Xenofonte endossa Plutarco, sem que o ateniense mencionasse o nome dos responsáveis pela introdução de riquezas em Esparta. Se a afirmação de Plutarco estiver correta, Lisandro foi quem promoveu a entrada de metais preciosos na pólis espartana, cujo efeito era sentido no período em que Xenofonte conviveu com os esparciatas. De fato, quando os espartanos passaram a valorizar a riqueza, já não era necessário um Lisandro para proporcionar-lhes o acesso a esta. Xenofonte (Lac. 14. 4) expôs que os esparciatas do século IV eram homens gananciosos que ansiavam pelo poder político e militar fora de sua pólis como harmostaí, pois assim não estariam limitados por suas leis. ${ }^{19}$

No que concerne a Lisandro, a posição política que detinha junto a Esparta e a maneira de agir diante dos aliados de sua pólis e dos seus próprios phíloi ${ }^{20}$ eram o reflexo da proeminência que a navarquia adquiriu no cenário geopolítico da Hélade. Nas palavras de Aristóteles, o cargo de navarco adquiriu influência o suficiente para rivalizar com os diarcas $^{21}$ da Lacedemônia (Arist. Pol. 1271a40). César Fornis (2016, p. 188) ampliou o nosso escopo ao ressaltar que a autoridade e a influência da navarquia em Esparta se tornaram extensas em virtude da importância que o combate marítimo adquiriu nos últimos anos da Guerra do Peloponeso. Efetivamente, sem a estratégia marítima adotada por Lisandro, os atenienses teriam conservado este conflito por mais tempo.

18 Ao se utilizar dos estudos de Eugene Cavaignac, James DeVoto (1982, p. 28) definiu as hetaireîai como uma associação de homens de tendência política oligárquica detentores de uma idade aproximada e que partilhavam interesses comuns em arte, música e política. Estes se reuniriam para se protegerem dos excessos dos democratas radicais, estando interessados na estabilidade social e na paz. Dessa maneira, as associações oligárquicas que Lisandro formou com a elite da Jônia teria se fundamentado na promessa de uma estabilidade político-social caso Esparta saísse vitoriosa na Guerra do Peloponeso. Isso justificaria o apoio incondicional que o navarco recebeu na Ásia Menor.

19 Para maiores informações sobre a presença da riqueza em Esparta, ainda no século V, vide Hodkinson (2000) e Powell (2010).

20 Substantivo cuja acepção seria “amigos”. O seu singular é phílos.

21 Esta palavra seria um composto duplo formado pelo prefixo di + arkheía, um nominativo plural neutro que provém de arkheîon e significa "magistratura". 
A atuação de Lisandro foi um dos fatores que assegurou a vitória peloponésia em Egospótamo, ${ }^{22}$ o que se somaria aos investimentos persas e ao descuido ateniense (Xen. Hell. II. 1. 20-31). Através do cruzamento dos vestígios documentais e da historiografia, esta foi uma das motivações dos autores clássicos e contemporâneos ao considerarem Lisandro um grande problema para Esparta. A postura e as decisões de Lisandro impactaram diretamente nas relações de poder no interior de Esparta e destas com os demais nós que compunham as suas redes. Nesse sentido, Lisandro representava os interesses de inúmeros grupos, mas também a discórdia de outros tanto em Esparta quanto na Hélade. ${ }^{23}$

Se considerarmos os escritos de Eurípides (Andr. 147-154), por exemplo, a riqueza era um dos atributos fundamentais da sociedade espartana. Através de uma conclusão, Isócrates afirmou que o descomedimento com a riqueza foi um problema para todas as póleis que alcançaram a hegemonia, tais como Atenas e Esparta:

[...] a dominação operou ruínas não somente em Atenas, mas também na pólis dos lacedemônios, de tal maneira que aqueles que têm o hábito de exaltar as virtudes de Esparta não podem argumentar que nós administramos mal os nossos negócios devido ao governo democrático, enquanto que os lacedemônios assumiram a supremacia e tiveram resultados felizes para todos e para si mesmos. Isso porque esse poder [a dominação] revelou a sua natureza [a ruína] muito mais rápido do que no nosso caso (Isoc. Peac. 95).

O que nos chamou a atenção foi o fato de autores em momentos distintos enfatizarem que um dos maiores problemas dos lacedemônios foi a incontinência para com a riqueza, sem que o nome de Lisandro fosse citado. Todavia, um elemento nestas redes políticas nos chama a atenção. Se de fato Lisandro foi um homem ganancioso, cujas atitudes prejudicaram Esparta direta ou indiretamente, o que motivou esta sociedade a mantê-lo como comandante em diversas circunstâncias, mesmo após o fim da Guerra do Peloponeso? Aqui tangenciamos uma parte do nosso pressuposto de análise acerca da desestruturação de Esparta. Tanto Lisandro quanto Agesilau teriam sido culpados por inserirem a pólis de Esparta e os seus cidadãos em uma condição de crise, da qual nunca mais os espartanos puderam sair. Não partilhamos desse posicionamento tão característico junto à historiografia tradicional e atenocêntrica, pois como esses homens poderiam ser os reflexos das mazelas espartanas se as suas ações estavam diretamente vinculadas aos interesses e as redes de sua pólis?

Essa perspectiva historiográfica minimizou as ações coletivas e o fato destes homens integrarem redes políticas que determinavam a maneira como deveriam agir. Se as afirmações de Xenofonte (Lac. 8. 1-5) estiverem corretas, o que diferenciava as autoridades de Esparta daquelas que existiam em outras póleis era o modo como os magistrados mais proeminentes se preocupavam em obedecer às leis. Com os basileîs não seria diferente, pois quando um dos heráclidas descumpria as determinações legais o mesmo poderia ser multado e até mesmo condenado a morte. ${ }^{24}$

22 Vide Assumpção (2019, p. 127-142).

23 O fato de Lisandro estar associado a Ágis II (Xen. Hell. II. 2. 7-8) fez com que o navarco o avisasse primeiro sobre a vitória em Egospótamo. Já as decarquías, segundo Plutarco (Lys. 13.3-5), foram estabelecidas no Egeu por Lisandro e sendo comandadas pelos seus hetaîroi. Nesse sentido, se considerarmos os aliados de Ágis que se beneficiaram com Lisandro e os grupos que passaram a exercer poder e influência no Egeu com as decarquías, notamos que Lisandro representou os interesses de diversas conexões políticas na Hélade.

24 No que tange à submissão dos basileîs à constituição espartana, destacamos o caso de Ágis II. Este foi multado pelos éforos, ao negligenciar um sacrifício em represália à oposição que estes últimos fizeram a um pedido seu (Plut. Lyc. 12. 3). Outro exemplo emblemático foi a condenação à morte sofrida pelo basileús Pausânias, o qual foi acusado de não cumprir os interesses de sua pólis diante de Atenas e Tebas (Xen. Hell. III. 5. 25). Temos também Agesilau que fora multado por manipular os cidadãos de Esparta e torná-los seus clientes (Plut. Ages. 2. 3). 
Diante dessas considerações verificamos que Lisandro e Agesilau estiveram submetidos aos valores e às prescrições que as leis de Esparta estabeleciam. De fato, seríamos ingênuos se acreditássemos plenamente que estes homens não poderiam subverter ou adaptar as ordens de sua pólis visando ao benefício pessoal. Todavia, consideramos que qualquer atitude de proporções exacerbadas e que fosse exponencialmente contrária aos interesses de Esparta levariam esses homens a serem punidos. Sendo assim, acusar o basileús Euripôntida e o navarco esparciata pelas suas ações nos levaria a concluir, de maneira precipitada, que a pólis espartana era indiferente a qualquer medida política tomada estes homens.

Contudo, Esparta e os éforos apoiaram a conduta e as atitudes que ambos os comandantes tiveram ao longo de suas vidas. Até mesmo as alianças que Lisandro edificou com persas, trácios e jônios tiveram o consentimento dos magistrados lacedemônios. Do mesmo modo, Agesilau recebeu todo o respaldo necessário para realizar uma expedição à Jônia no início do seu reinado, além de atuar como mercenário no Egito no final de sua vida. Tais argumentos pretendem minimizar a forma como a historiografia interpretou as atitudes de Lisandro e Agesilau, uma vez que Esparta se beneficiou amplamente com as conquistas obtidas por estes comandantes. Logo, munidos do arcabouço teórico das redes políticas, destacamos que Lisandro esteve imerso nas conexões políticas de sua pólis, o que impactou em muitas de suas decisões. Entretanto, não negamos os interesses particulares do navarco, os quais permitiram que ampliasse as suas relações políticas com homens poderosos na Hélade e no Império Aquemênida. Logo, refutamos a ideia de que Lisandro foi o responsável por corromper os valores espartanos, visto que as suas medidas almejavam, sobretudo, a obtenção de recursos para conservar a supremacia de Esparta com a vitória em Egospótamo.

Independentemente de qualquer ameaça que Lisandro representasse, muitas de suas atitudes receberam o apoio e o respaldo do basileús Ágis II. O referido Euripôntida foi identificado como um dos homens mais poderosos de sua época, tendo em vista a sua experiência militar e o fato de ter herdado as redes políticas de seu pai, Arquídamos II. Xenofonte (Hell. II. 2. 7-8) nos forneceu indícios da relação política que havia entre o navarco e Ágis II, pois ao vencer os atenienses em Egospótamo, Lisandro se dirigiu a Samos e, dali, enviou uma mensagem direta ao basileús Euripôntida notificando-o do feito militar. Em seguida, Lisandro pontuou que estava partindo com embarcações para o Pireu, para promover um cerco a Atenas. Nesse período a dinastia dos Ágidas era governada por Pausânias, o qual foi designado por Esparta para liderar um contingente de apoio para ampliar a ofensiva aos atenienses. Esse trecho do discurso de Xenofonte merece atenção pelo fato de Lisandro notificar, primeiramente, Ágis e depois sua pólis sobre a vitória em Egospótamo. Mesmo assim, se o navarco não tivesse relações políticas com o Euripôntida, nada o impediria de avisar Pausânias de suas ações militares.

De todo modo, a documentação literária nos chama a atenção para o fato de que Lisandro, por ter nascido em uma família sem recursos, não tinha direitos políticos em Esparta (Plut. Lys. 2. 1, 2. 3). Paul Cartledge (2003, pp. 183-184) destacou que ele obteve a cidadania e, consequentemente, a indicação para um cargo militar proeminente por ter integrado a rede política de clientelismo da dinastia Euripôntida. ${ }^{25}$ Jacqueline Christien e Françoise Ruzé (2007, p. 129) expuseram que a prática do clientelismo era comum entre os membros da realeza lacedemônia, através da qual poderiam ampliar as suas redes políticas no âmbito políade. Como em Esparta os

$25 \mathrm{O}$ pertencimento de Lisandro à rede de clientelismo de Ágis e dos Euripôntidas foi mencionada na nota 23. Fornis (2018) nos permite conjeturar que Lisandro se aproximou de Agesilau com o intuito de obter benefícios no interior da rede de clientelismo dos Euripôntidas. 
jovens que não realizassem a paideía esparciata estavam excluídos da cidadania, homens de recursos e/ou da realeza financiavam a educação e os gastos que esses sujeitos teriam para se tornar cidadãos em troca da sua lealdade e de suas famílias. As considerações apresentadas ressaltam que entre os espartanos e os lacedemônios a formação de redes políticas eram mecanismos adequados para se alcançar objetivos políticos, sociais e econômicos.

No interior da Teoria de Redes, ao invés de abordarmos essa prática como clientelismo, poderíamos falar de auxílio social. Essa característica emerge em redes densas, nas quais os seus membros tentam obter benefícios com aqueles que estão em um nível político-social mais elevado. Para os líderes (nós centrais) de uma rede é interessante os benefícios atribuídos aos atores de menores recursos, tendo em vista a importância destes para que se desenvolvam sentimentos com a sua liderança e legitimem o seu poder junto aos demais nós da rede. Afinal, a autoridade de um líder se amplia pela influência social que exerce junto ao seu grupo social (Kadushin, 2012, pp. 60-61, 87). Diante do cenário político de Esparta e tomando o exemplo das casas reais da Lacedemônia, supomos que o financiamento de jovens de famílias sem recursos era uma estratégia política admirável, posto que os basileîs lacedemônios careciam de plenos poderes políticos. Essa atitude garantia-lhes a ampliação da sua autoridade através da influência sobre os cidadãos mais pobres e pela confiança que estes atribuíam aos seus benfeitores.

Com isso, destacamos que as redes políticas são compostas pelas relações/conexões promovidas por um sujeito e/ou o seu grupo social. Essas relações atuan como os nós destas redes. Todavia, uma vez que um grupo de pessoas junto de seus principais representantes formam relações políticas, estas se tornam o reflexo, direto ou indireto, de sua autoridade no interior de sua sociedade ou de seu período histórico. Nesse caso, temos por hipótese que Arquídamos II, cujo governo durou de aproximadamente 469 a 427, inseriu Lisandro e a sua família na rede política de clientelismo da dinastia Euripôntida. A partir de então, todas as atitudes promovidas por Lisandro e os seus parentes mais próximos estariam vinculadas à esta linhagem real. Com a morte de Arquídamos o cargo de basileús coube ao seu filho mais velho, Ágis II, o qual herdou todas as suas redes políticas - tanto dentro quanto fora da Lacedemônia -. Essa conjuntura fez com que Lisandro se aproximasse de Ágis II, passando a representá-lo e a obedecê-lo como uma dívida de gratidão hereditária.

\section{Considerações finais}

Mediante o exposto concluímos que as atividades políticas de Lisandro estavam diretamente atreladas aos interesses de Esparta, servindo como um instrumento de ampliação da autoridade político-militar desta pólis sobre uma extensão cada vez mais ampla do Mediterrâneo. Esse cenário não inviabilizaria as medidas do navarco em prol de seu benefício pessoal, entretanto, não podemos considerá-lo um problema para Esparta, haja vista que grande parte de suas ações foram do conhecimento dos magistrados espartanos. Nesse sentido, o comparativismo proveniente da História Cruzada nos permitiu dialogar com indícios literários de temporalidades distintas, as quais tiveram as suas variáveis contempladas nesse processo para evitarmos anacronismos históricos diante das informações obtidas.

Do mesmo modo, ao dialogarmos com os estudos da Análise de Discurso francesa e a Teoria de Redes verificamos que a documentação empregada esteve vinculada ao contexto e a comunidade discursiva de seus autores, os quais também detinham interesses particulares ao promoverem as suas obras. Por fim, não concordamos 
com o viés historiográfico hegemônico, cuja premissa fundamental se estruturou na tentativa de responsabilizar um ator social pela desestruturação de toda uma sociedade. Julgamos essa perspectiva simplista, afinal, por não valorizar adequadamente o papel social dos autores da documentação utilizada e nem mesmo as suas respectivas intenções ao desenvolvê-las, culminando em generalismos e deturpações historiográficas no que concerne a história espartana. 


\section{Bibliografia}

" Assumpção, L. F. B. de. (2019). A representação da métis do esparciata Lisandro na Batalha de Egospótamo (405 a.C.). Romanitas - Revista de Estudos Grecolatinos, 13, 127-142.

" Beck, H. (2008). Prologue. En J. Buckler y H. Beck (Eds.), Central Greece and the Politics of Power in the Fourth Century B.C. (1-30). Cambridge: Cambridge University Press.

" Beck, H. y Funke, P. (2015). An introduction to federalism in Greek antiquity. En H. Beck y P. Funke (Eds.), Federalism in Greek Antiquity (1-29). Cambridge: Cambridge University Press.

» Buckler, J. (2003). Aegean Greece in the Fourth Century B.C. Leiden: Brill.

»Canfora, L. (2016). Tucidide: la menzogna, la colpa, l'esilio. Bari: Editori Laterza.

"Cartledge, P. (1987). Agesilaos and the Crisis of Sparta. Baltimore: The Johns Hopkins University Press.

" Cartledge, P. (2003). The Spartans: An Epic History. Londres: Pan Books.

"Christien, J. y Ruzé, F. (2007). Sparte: Géographie, mythes et histoire. Paris: Armand Colin.

» David, E. (1981). Sparta between Empire and Revolution (404-243 B.C.): Internal Problems and Their Impact on Contemporary Greek Consciousness. Nova lorque: Arno Press.

"De Certeau, M. (2008). A Escrita da História. Rio de Janeiro: Forense-Universitária.

»DeVoto, J. (1982). Agesilaos II and the Politics of Sparta, 404-377 B.C. Chicago: Loyola University of Chicago (Tese).

》Finley, M. (1981). Economy and Society in Ancient Greece. Nova lorque: The Viking Press.

» Fornis, C. (2016). Esparta: La historia, el cosmos y la leyenda de los antiguos espartanos. Sevilla: Editorial Universidad de Sevilla.

»Fornis, C. (2018). El poco espartano patronazgo de Agesilao. En J. Pascual, B. AntelaBernárdez y D. Castro (Eds.), Cambio y pervivencia. El mundo griego en el siglo IV a.C. (125-139). Madrid: Ediciones Universidad Autónoma de Madrid.

» Funke, P. (2009). Between Mantinea and Leuctra. En P. Fnke y N. Luraghi (Eds.), The Politics of Ethnicity and the Crisis of the Peloponnesian League (1-14), Cambridge: Harvard University Press.

" Hamilton, C. (1979). Sparta's Bitter Victories: Politics and Diplomacy in the Corinthian War. Ithaca: Cornell University Press.

» Hamilton, C. (1991). Agesilaus and the Failure of Spartan Hegemony. Ithaca: Cornell University Press.

"Hanson, V.D. (2012). Uma Guerra sem igual: como atenienses e espartanos lutaram na Guerra do Peloponeso. Rio de Janeiro: Record.

" Herman, G. (1987). Ritualised Friendship and the Greek City. Cambridge: Cambridge University Press.

"Hodkinson, S. (2000). Property and Wealth in Classical Sparta. Swansea: The Classical Press of Wales.

" Kadushin, C. (2012). Understanding Social Networks: theories, concepts, and findings. Oxford: Oxford University Press. 
Kagan, D. (1969). The Outbreak of the Peloponnesian War. Ithaca: Cornell University Press.

» Kagan, D. (1974). The Archidamian War. Ithaca: Cornell University Press.

» Kagan, D. (1981). The Peace of Nicias and The Sicilian Expedition. Ithaca: Cornell University Press.

» Kagan, D. (1987). The Fall of the Athenian Empire. Ithaca: Cornell University Press.

» Konstan, D. (2005). A amizade no mundo clássico. São Paulo: Odysseus Editora.

» Lemercier, C. (2015). Formal Network Methods in History: Why and How?. En G. Fertig (Ed.), Social Networks, Political Institutions, and Rural Societies (281-310). Turnhout: Brepols.

» Low, P. (2007). Interstate Relations in Classical Greece: Morality and Power. Cambridge: Cambridge University Press.

» Maingueneau, D. (1997). Novas Tendências em Análise do Discurso. Campinas: Editora da UNICAMP.

» Malkin, I. (2011). A Small Greek World: Networks in the Ancient Mediterranean. Oxford: Oxford University Press.

» Mossé, C. (1968). Les institutions politiques grecques à l'époque Classique. Paris: Armand Colin.

» Pires, F. M. (2006). Mithistória (Vol. II). São Paulo: Humanitas.

»Powell, A. (2001). Athens and Sparta: Constructing Greek Political and Social History, from 478 BC. Londres: Routledge.

» Powell, A. (2010). Divination, Royalty and Insecurity, En A. Powell y S. Hodkinson (Eds.), Sparta: The Body Politic (85-136). Swansea: The Classical Press of Wales.

» Raaflaub, K. (2006). Thucydides on Democracy and Oligarchy. En A. Rengakos y A. Tsakmakis (Eds.), Brill's Companion to Thucydides (189-223). Leiden: Brill.

»Rusch, S. M. (2011). Sparta at War: Strategy, Tactics, and Campaigns, 550-362 BC. Londres: Frontline Books.

»Starr. C. G. (1965). The Credibility of Early Spartan History. Historia, 14, 257-272.

»Ste. Croix, G. E. M. (1972). Spartan Foreign Policy, and the Peloponnesian League. En G. E. M. Ste. Croix (Ed.), The Origins of the Peloponnesian War (89-166). Londres: Duckworth.

" Taylor, M. (2010). Thucydides, Pericles, and the Idea of Athens in the Peloponnesian War. Cambridge: Cambridge University Press.

» Tritle, L. (1997). Introduction. En L. Tritle (Ed.), The Greek World in the Fourth Century: From the Fall of the Athenian Empire to the Successors of Alexander (1-7). Londres: Routledge.

»Vlassopoulos, K. (2009). Beyond and Below the Polis: Networks, Associations, and the Writing of Greek History. En L. Malkin, C. Constantakopolou y K. Panagopoulou (Eds.), Greek and Roman Networks in the Mediterranean (12-23). Londres: Routledge.

»Werner, M. y Zimmermann, B. (2003). Pensar a história cruzada: entre empiria e reflexividade. Textos de História, 11(1/2), 89-127.

»Westlake, H. D. (1971). Thucydides and the Uneasy Peace - A Study in Political Incompetence. The Classical Quarterly, 21(2), 315-325. 